\title{
A cross-sectional study on the level of job stress among nursing staff and its relation with demographic variables and their work pattern in a tertiary care teaching hospital in Surendranagar, Gujarat
}

\author{
Krupal Jagdishchandra Joshi ${ }^{1}$, Kishor Mansukhbhai Sochaliya ${ }^{2}$, Girija Prabhakar Kartha ${ }^{2}$
}

${ }^{1}$ Associate Professor, Department of Community Medicine, C. U. Shah Medical College, Surendranagar, Gujarat; ${ }^{2}$ Professor, Department of Community Medicine, C. U. Shah Medical College, Surendranagar, Gujarat;

\begin{tabular}{|c|c|c|c|c|c|c|c|}
\hline Abstract & Introduction & Methodology & Results & Conclusion & References & Citation & Tables / Figures \\
\hline \multicolumn{8}{|c|}{ Corresponding Author } \\
\hline \multicolumn{7}{|c|}{$\begin{array}{l}\text { Dr Krupal J Joshi, “Aashutosh”, Block - 87, Sanjivni Society, Ratanpar, Surendranagar, Gujarat- } 363020 \\
\text { E Mail ID: dr.krupaljoshi@gmail.com }\end{array}$} & 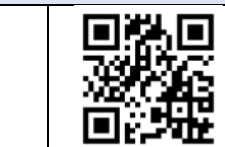 \\
\hline
\end{tabular}

\section{Citation}

Joshi KJ, Sochaliya KM, Kartha GP. A cross-sectional study on the level of job stress among nursing staff and its relation with demographic variables and their work pattern in a tertiary care teaching hospital in Surendranagar, Gujarat Indian J Comm Health. 2020;32(2):404-410.

Source of Funding: Nil Conflict of Interest: None declared

\section{Article Cycle}

Received: 27/05/2020; Revision: 05/06/2020; Accepted: 17/06/2020; Published: 30/06/2020

This work is licensed under a Creative Commons Attribution 4.0 International License.

\section{Abstract}

Introduction: The nursing profession is known to be stressful throughout the world. It contributes to various physical and psychological health problems in nurses, which ultimately influencing on their performance and efficiency of work. Objective: To measure the level of job stress among nurses and to find out its relationship with demographic variables and working pattern. Methods: Study was done among 102 nurses in a tertiary care hospital of Surendranagar district from February to March 2020. The level of job stress was measured by a set of 14 questions which are directly related to job stress and response was collected on a five-point Likert Scale. Results: This study revealed, moderate and severe level of job stress among 53\% and $45 \%$ of nurses respectively. The job stress had no statistically significant association with demographic variables like age and gender. However, job stress had an inverse correlation with the factors like work experience, shift timings and working hours. Conclusion: All the study participants were suffering from mild to severe level of job stress. Younger age group and female nurses were commonly affected with job stress. Work stress was also found more prevalent in nurses with lesser experience, rotational shift and more working hours.

\section{Keywords}

Job stress; Nursing staff; Demographic variable; Work pattern

\section{Introduction}

Stress is an unavoidable characteristic of life and work. In any job, there are wide variety of potential causes of stress. (1) Stress can be defined as the degree to which you feel overwhelmed or unable to cope as a result of pressures that are unmanageable. (2)

Occupational stress and health at working place have become key issues of concern over the past few years, both internationally and nationally. Occupational stress is defined as the perception of a discrepancy between environmental demands (stressors) and individual capacities to fulfill these demands. (3)

Stress in nurses is an endemic problem. The nursing profession is known to be stressful throughout the world and has detrimental effects on the physical and psychological well-being of an individual's health. It contributes to health problems in nurses and decreases their efficiency. (4) Research for the past years shows that, signs of occupational stress appear to be rising among nurses which has been referred to several factors ranging from downsizing, restructuring, and merging to role boundary and responsibility. $(5,6)$

\section{Aims \& Objectives}

1. Determine the level of job stress among nursing staff

2. Find out the relationship between job stress with demographic variable and work pattern

\section{Material \& Methods}

A cross sectional study was conducted in tertiary care teaching hospital situated at Surendranagar district of 
Gujarat state. The data was collected between February 2020 to March 2020 through a self-administered pretested proforma. A total of 102 nurses working in the eleven different departments of hospital were included in the study randomly. While the nurses who did not gave consent, non-cooperative or not responded the questionnaires properly were excluded from the study.

The data was collected on demographic variables like age, sex, annual income and on working pattern like duration of work, shift timings, frequency of shift change in a week, number of working hours per week, number of hours of overtime in a week. To determine the level of job stress, a set of 14 questions which are related to job stress and directly linked with the nursing job were identified. Nurses were asked to express their opinion for each question on a five-point Likert Scale i.e., Strongly Disagree, Disagree, Neither Disagree or Agree, Agree \& Strongly Agree. On this scale, the scores were directly related to the level of stress, i.e., higher score meant more stress. Minimum scores that could be obtained by each nurse were 14 (one point for each 14 questions) and maximum scores that could be obtained were 70 (5 points for each 14 questions). The final job stress was then classified based on total points for each nurse as: no stress - 14 points, mild stress - 15 to 32 points, moderate stress - 33 to 50 points and severe stress - 51 to 70 points.

Prior permission and ethical clearance for the study were obtained from the Institutional Ethical Committee. The collected data were then entered and analyzed in Microsoft Office Excel 2016. Descriptive statistics like Percentage, Mean and Standard Deviation were used to summarize the data. Chi-square test and Spearman's Correlation Coefficient was used for statistical analysis.

\section{Results}

Primary Data was collected through administering questionnaires among 102 nursing staffs of tertiary care teaching hospital in Surendranagar. Out of these, majority of nurses (64.71\%) were between the age group of 20-30 years followed by $30-40$ years $(22.55 \%)$. Very minimal study participants were above the age of 40 years i.e., $12.74 \%$. The mean age of the participants was 29.79 with SD of \pm 8.81 . According to gender, there is no static difference observed $(56.86 \%$ females against $43.14 \%$ males). Around two third (63.74\%) of the respondents were having their annual income between 1 lac to 5 lacs. While $19.6 \%$ were having 5 lacs or more and $15.68 \%$ were having 50,000 to 1 lac as an annual income.(Table 1) In terms of working pattern, $56.86 \%$ of the nursing staff were having work experience of less than 5 years. The mean years of work experience was $6.10 \pm 7.65$ (SD). Regarding the shift timing of the respondents, it was seen that nearly three fourth $(71.57 \%)$ of the study participants were having 8 hours shift in a day on a rotational basis. While one fourth (25.49\%) were having permanent day shift. Of the 102 nursing staff enrolled in the study, one third (33.33\%) had fixed shift timing in a week. While in $15.69 \%$ and $31.37 \%$ of the nursing staff, shift was changed 2 times and more than 2 times in a week respectively. $14.71 \%$ of the nurses will be on call i.e., the work was being assigned in case of sickness or leaves of the routine nursing staff. It was observed that most of the nursing staff $(82.36 \%)$ were working for around $41-45$ hours per week with mean working hours of $42.37 \pm 1.89$ (SD). When they were asked for hours of overtime in a week, around $60 \%$ of nursing staff responded that they did not do any overtime in a week while $30.39 \%$ of the staff did overtime of $1-5$ hours followed by $8.82 \%$ with $6-10$ hours of overtime. (Table 2)

Department wise distribution of study participants is shown in (Figure 1). And it was found that majority of the nursing staff were working in the Paediatrics (15.7\%), General Medicine (14.8\%), General Surgery (13.8\%), Obstetrics \& Gynaecology (11.7\%), Emergency (11.7\%) and Orthopaedics (10.8\%) Departments.

When the scores for level of job stress was analyzed, it was observed that around $98 \%$ of the nursing staff were having either moderate $(52.95 \%)$ or severe $(45.09 \%)$ type of job stress. Only $1.96 \%$ of the nurses were having mild job stress, while not a single respondent was in no stress category.(Table 3 )

Amongst all the 102 study participants, level of stress was found higher in the age group of 20-30 years (severe stress in $73.9 \%$ and moderate stress in $57.4 \%$ ) followed by $30-40$ years (severe stress in $17.4 \%$ and moderate stress in $25.9 \%)$. However, none of the difference was found statistically significant $(P=0.29)$. Gender wise distribution of job stress shows that the level of severe stress was the same both in female and male while moderate stress was higher in female $(61.1 \%)$ as compare to male (38.9\%). And the difference was also not statistically significant $(P=$ 0.24). (Table 4)

When the association between the level of job stress and work pattern of study participants was analyzed, it was seen that years of experience has some role in decreasing the level of stress as it was found higher among the nurses whose job experience was less than 5 years. Although the difference was not statistically significant $(P=0.56)$. Stress level was also observed to be highest (> 70\% of both moderate $\&$ severe stress) among the nursing staff having rotating 8 hours shift in a week as compared to other shift timings like rotating 12 hours shift or permanent day/evening/night shift. There was little or no difference seen in the level of job stress among the study participants whose shift was either not changed or changed 2 or more than 2 times or on call in a week. The difference was also not statistically significant $(P=0.74)$. (Table 5)

Among the nursing staff who were working for more than 40 hours in a week, the job stress level was found to be higher $(84.8 \%$ having severe stress and $98.1 \%$ having moderate stress). The difference was not statistically significant $(P=0.17)$. The level of severe stress was found 
nearly the same among the nursing staff who were/weren't doing overtime $(52.2 \%$ and $47.8 \%$ respectively). While moderate level of job stress was observed to be $66.7 \%$ among the nurses without overtime, $20.4 \%$ among $1-5$ hours of overtime and $12.9 \%$ in nurses doing overtime of more than 5 hours. However, the difference was not found statistically significant $(P=$ 0.07). (Table 5)

\section{Discussion}

The main purpose of the study was to identify the level of job stress and its association with socio-demographic factors and work pattern among the nursing staff of a tertiary care hospital in Surendranagar.

In present study $86.27 \%$ nurses were below 40 years of age group. Similar result was also found by Dr. Tessy Treesa Jose \& Dr. Sripathy M Bhat in their study.(7) According to gender, female participants were $56.86 \%$ compared to $43.14 \%$ male nurses in the current study. However, in the study done by K. Vijaya Nirmala \& M. Suresh Babu and Simiret Tekeletsadik et al. male nurses were higher compared to female nurses. $(8,9)$

In this study $76.46 \%$ of the nurses were having less than 10 years of work experience. Similarly in the study of Huda M. Al-Makhaita et al, it was observed that in secondary level hospital $82.4 \%$ of the nurses were having less than 10 years of experience.(10) In a study conducted by Abdul Salam and Munir Abu-Helalah in a King Abdullah International Medical Research Center, Saudi Arabia, $85.9 \%$ of the health care professionals had workload of more than 40 hours per week while it was $91 \%$ in our study.(11) Similarly in a study done by Simiret Tekeletsadik et al. it was observed that $35.9 \%$ and $64.1 \%$ of the nurses were working in a fixed and rotating shift duty in contrast to $26.47 \%$ and $73.53 \%$ in present study.(9) The present study showed that among the total 102 nursing staff, $1.96 \%$ were having mild stress, $52.95 \%$ moderate stress and $45.09 \%$ were suffering from severe type of job stress. In contrast to our study, Badil et al had shown in their study that mild, moderate and severe level of job stress among the nurses of Karachi, Pakistan was $25.28 \%, 39.62 \%$ and $35.09 \%$ respectively.(12) Similarly, in a study conducted by Arash Najimi et al. on causes of job stress in nurses of Kashan Hospital, Iran showed that the level of no stress, mild and moderate stress was 3.2\%, 93.1\% and 3.7\% respectively.(13) Several other studies carried out by K. Vijaya Nirmala and M. Suresh Babu in eight different hospitals of South India and Tadesse Dagget et al. in Zimma zone public hospitals, South West Ethiopia reported that mild, moderate and high level of job stress was $25.75 \%, 48.17 \%, 26.08 \%$ and $33.3 \%$, 34\%, $32.7 \%$ respectively. $(8,14)$

In this study, as the age of the study participants increased the level of the job stress decreased. Majority of the nursing staff who had moderate stress belonged to the age group of $20-30$ years $(57.4 \%)$ followed by $30-40$ years
(25.9\%). Only $16.67 \%$ of the nursing staff with moderate stress were of more than 40 years of age group. The level of severe job stress was also seen higher among the nurses of younger age (73.9\% among $20-30$ years of age). The reason behind this may be due to more years of experience and at some level due to their settled life. Nearly similar results were observed in the study of $\mathrm{K}$. Vijaya Nirmala and M. Suresh Babu i.e., 54.7\% and $44.4 \%$ of the health care professionals in the age group of 20-30 years were feeling moderate and high level of work stress respectively and the statistical difference was also significant $(P<0.05)$.(8) The above findings is also consistent with the results of study done by Arash Najimi et al. where the level of job stress was higher among nurses of younger age group.(13) While in a study conducted by Dimitra Chatzigianni et al. among nurses working in a regional public general hospital in northern Greece, the level of occupational stress was expressed higher among the nurses of 30-34 years of age groups as compared to younger one.(15)

The level of moderate stress was found higher among female $(61.1 \%)$ compared to male nurses. But there was no gender wise difference observed for severe type of work stress. Similarly, in the findings of the study done by Badil et al, moderate and severe level of work stress was found more among females ( $59 \%$ \& 56\% respectively) as compared to male nursing staff.(12) However, the results of the study done by Azam Faraji et al. was not consistent with the present study.(16)

In present study it was observed that there was no statistically significant relationship found between the job stress among the nursing staff and their work experience, shift timing, shift change, working hours and hours of overtime. Meysam Safi Keykaleh et al. also found similar results in their study about no significant relationship between job stress and type of employment, work experience and work shift among nurses.(17) Further in a study carried out by Mortaghy et al. on 155 nurses of teaching hospitals of Zanjan, no significant relation was found between work shift and occupational stress.(18) However contrary to this, several studies carried out by Seyed Ehsan Samaei et al., Alessandra Buja et al. and Eriksen $\mathrm{W}$ et al. observed a significant relation between work shift and job stress. $(19,20,21)$ In this study, a weak negative correlation was found between the level of work stress and work experience $(r=-0.14)$, shift timings $(r=-$ $0.01)$ and working hours per week $(r=-0.22)$. Similarly, Letwak S. and Buck R. in his study on factors influencing work productivity and intent to stay in nursing reported that there was a negative correlation between job stress and work experience.(22) In the present study, there was no observed difference found between the occupational stress and working hours or overtime. However, these findings were not consistent with the study done by Seyed Ehsan Samaei et al., who reported that the increased working hours of the nurses during the week was a 
predictive variable in the development of occupational stress.(19) In addition, Erikson W et al and Aditi Prasad Chaudhari et al. were also found similar significant relation between occupational stress and working hours. $(21,23)$ While in a study carried out by Nandita Kshetrimayum et al. on stress among staff nurses in Mysore city of India reported no significant relation between job stress and work experience.(24)

\section{Conclusion}

This study was aimed to identify the level of job stress among the nurses of a tertiary care teaching hospital of Surendranagar and to associate it with the demographic factors and their working condition. Based on the results of this study, it was concluded that majority of the nursing staff suffered from moderate to severe level of job stress. Young age group nurses were found to be highly affected with job stress. The findings also suggest that less work experience, rotational work shift and more working hours per week had a significant role in developing job stress.

\section{Recommendation}

It is recommended to conduct a stress management seminar at a regular interval in the hospital for all the health care providers. It is also suggested that every nurse is being screened for a level of job stress on a regular basis. Their quality of work should also be appreciated and motivated with a reward to encourage them. It is also recommended, that this study can be expanded by including more health care institutions both from urban and rural areas.

\section{Relevance of the study}

In the current stressful life pattern, job related problems increase the stress and leads to many health-related issues which includes psychiatric as well as physical health problems. In this study an attempt is made to identify those issues, so that appropriate preventive measures could be initiated which would be of immense help to the professionals and the community at large.

\section{Authors Contribution}

All authors have contributed equally.

\section{References}

1. Akinboye, J.O., Akinboye, D.O., Adeyemo, D.A. Coping with Stress in Life and at the Work place. Stirlin- Hordon Publishers (Nig). Ltd. 2002

2. Stress-mentalhealth.org.uk. Mental Health Foundationh: Definition of stress. Available from: https://www.mentalhealth.org.uk/a-to-z/s/stress. Last Accessed on $29 / 05 / 2020$.

3. Topper, E. F. Stress in the Library. Journal of New Library 2007;108(11/12):561-564.

4. Olayinka AO, Osamudiamen OS. Occupational stress management among nurses in selected hospital in Benin City, Edo state, Nigeria. Eur J Exp Biol 2013;3:473-481

5. Nedd N. Perceptions of empowerment and intent to stay. Nurs Econ. 2006 Jan-Feb;24(1):13-8, 3. PubMed PMID: 16583601. [PubMed]

6. Tzeng HM. The influence of nurses' working motivation and job satisfaction on intention to quit: an empirical investigation in
[A cross-sectional...] | Joshi KJ et al Taiwan. Int J Nurs Stud. 2002 Nov;39(8):867-78. doi: 10.1016/s0020-7489(02)00027-5. PubMed PMID: 12379304.[PubMed]

7. Dr. Tessy Treesa Jose \& Dr. Sripathy M. Bhat. A descriptive study on stress and coping of nurses working in selected hospitals of Udupi and Mangalore districts Karnataka, India. IOSR Journal of Nursing and Health Science 2013;3(1) Version 1:10-18

8. K. Vijaya Nirmala, M. Suresh Babu. Job Stress among Health Care Professionals in Selected Hospitals with Special Reference to Age and Gender. International Journal of Science and Research 2015;4(6):1625-1629

9. Tekeletsadik S, Mulat H, Necho M, Waja T. Occupational stress and its associated factors among health care professionals working at a setting of a specialized mental hospital, Addis Ababa, Ethiopia, 2017: A Hospital-Based Cross-Sectional Study. J Psychol Psychother 2020;10(1):1-8

10. Huda M. Al-Makhaita, Amr A Sabra, Ahmed S Hafez. Job performance among nurses working in two different health care levels, eastern Saudi Arabia: a comparative study. International journal of medical science and public health 2014;3(7):832-837

11. Abdul Salam, Munir Abu-Helalah, Shari L. Jorissen, Khalid Niaz, Abuelgasim Mansour, Ali Al Qarni. Job stress and job satisfaction among health care professionals. European Scientific Journal 2014;10(32):156-173

12. Badil, Hakim Shah, Syed Arif Ali, Muhammad Arsalan Siddiqui. Severity of Stress in Nurses Everyday Life in Karachi, Pakistan. J Liaquat Uni Med Health Sci 2017;16(1):62-67

13. Najimi A, Goudarzi AM, Sharifirad G. Causes of job stress in nurses: A cross-sectional study. Iran J Nurs Midwifery Res. 2012 May;17(4):301-5. PubMed PMID: 23833631; PubMed Central PMCID: PMC3702151[PubMed].

14. Dagget $T$, Molla A, Belachew T. Job related stress among nurses working in Jimma Zone public hospitals, South West Ethiopia: a cross sectional study. BMC Nurs. 2016;15:39. doi: 10.1186/s12912-016-0158-2. eCollection 2016. PubMed PMID: 27313502; PubMed Central PMCID: PMC4910212.[PubMed]

15. Chatzigianni D, Tsounis A, Markopoulos N, Sarafis P. Occupational Stress Experienced by Nurses Working in a Greek Regional Hospital: A Cross-sectional Study. Iran J Nurs Midwifery Res. 2018 Nov-Dec;23(6):450-457. doi: 10.4103/ijnmr.IJNMR_120_17. PubMed PMID: 30386395; PubMed Central PMCID: PMC6178576.[PubMed]

16. Azam Faraji, Mahtab Karimi, Seyyed Mohsen Azizi, Maryam Janatolmakan \& Alireza Khatony. Occupational stress and its related demographic factors among Iranian CCU nurses: a crosssectional study. BMC Res Notes 2019; 12, 634

17. Keykaleh MS, Safarpour $H$, Yousefian $S$, Faghisolouk $F$, Mohammadi E, Ghomian Z. The Relationship between Nurse's Job Stress and Patient Safety. Open Access Maced J Med Sci. 2018 Nov 25;6(11):2228-2232. doi: 10.3889/oamjms.2018.351. eCollection 2018 Nov 25. PubMed PMID: 30559893; PubMed Central PMCID: PMC6290432[PubMed].

18. Masoomeh Mortaghi ghasemi, Zeinab Ghahremani, Amir Vahedian azimi, Fatemeh Ghorbani. Nurses job stress in therapeutic educational centers in Zanjan. J Res dev Nurs Midwifery. 2011;8(1):42-51

19. Seyed Ehsan Samaei et al. Evaluating the status of occupational stress and identifying its related risk factors among nurses in Babol City, Northern Iran: A cross-sectional study. IJOH. 2018;10:60-66

20. Buja A, Zampieron A, Mastrangelo G, Petean M, Vinelli A, Cerne D, Baldo V. Strain and health implications of nurses' shift work. Int J Occup Med Environ Health. 2013 Aug;26(4):511-21. doi: 10.2478/s13382-013-0122-2. Epub 2014 Jan 25. PubMed PMID: 24057261.[PubMed]

21. Eriksen W, Tambs K, Knardahl S. Work factors and psychological distress in nurses' aides: a prospective cohort study. BMC Public Health. 2006 Nov 28;6:290. doi: 10.1186/1471-2458-6-290. 
INDIAN JOURNAL OF COMMUNITY HEALTH / VOL 32 / ISSUE NO 02 / APR - JUN 2020 PubMed PMID: 17132172; PubMed Central PMCID: PMC1693921.[PubMed]

22. Letvak S, Buck R. Factors influencing work productivity and intent to stay in nursing. Nurs Econ. 2008 May-Jun;26(3):159-65. PubMed PMID: 18616053.[PubMed]
[A cross-sectional...] | Joshi KJ et al

23. Chaudhari AP, Mazumdar K, Motwani YM, Ramadas D. Aprofile of occupational stress in nurses. Ann Indian Psychiatry 2018;2:109114

24. Kshetrimayum Nandita, Bennadi Darshana, Siluvai Sibyl. Stress among staff nurses: A hospital-based study. Journal of Nature and Science of Medicine 2019;2(2):95-100

\section{Tables}

TABLE 1 DISTRIBUTION OF STUDY PARTICIPANTS ACCORDING TO THEIR SOCIO-DEMOGRAPHIC CHARACTERISTICS ( $\mathrm{N}=102)$

Demographic variable

Number
Age wise Distribution (Years)

20-30

$30-40$

40-50

50-60

Female

Male

Less Than $\mathbf{5 0 0 0 0}$

50000-1,00,000

$1,00,000$ To $5,00,000$

$5,00,000$ And Above
66

23

8

5

Gender wise Distribution

44

Distribution according to Annual Income

1

16

65

20

\section{1}

Percentage

Mean \pm SD

\begin{tabular}{c|}
\hline 64.71 \\
\hline 22.55 \\
\hline 7.84 \\
\hline 4.9
\end{tabular}

56.86

43.14

0.98

15.68

63.74

19.6

TABLE 2 DISTRIBUTION OF STUDY PARTICIPANTS ACCORDING TO THEIR WORKING PATTERN (N = 102)

Working pattern Number $\quad$ Percentage Mean \pm SD

\begin{tabular}{|c|c|c|c|}
\hline \multirow{2}{*}{\multicolumn{4}{|c|}{ Years of work experience }} \\
\hline & & & \\
\hline Less than 5 year & 58 & 56.86 & \multirow{3}{*}{$6.10 \pm 7.65$} \\
\hline 5 To 10 year & 20 & 19.6 & \\
\hline More than 10 year & 24 & 23.54 & \\
\hline \multicolumn{4}{|c|}{ Shift timing } \\
\hline Rotating 8 hours shift & 73 & 71.57 & \\
\hline Rotating 12 hours shift & 2 & 1.96 & \\
\hline Permanent day shift & 26 & 25.49 & \\
\hline Permanent evening shift & 1 & 0.98 & \\
\hline Permanent night shift & 0 & 0 & \\
\hline \multicolumn{4}{|c|}{ Shift change in a week } \\
\hline Does not change & 34 & 33.33 & \\
\hline Change 2 times & 16 & 15.69 & \\
\hline More than 2 times & 32 & 31.37 & \\
\hline On call & 15 & 14.71 & \\
\hline In stand by & 5 & 4.9 & \\
\hline \multicolumn{4}{|c|}{ Working hours per week } \\
\hline 36-40 hours & 9 & 8.82 & \multirow{3}{*}{$42.37 \pm 1.89$} \\
\hline 41-45 hours & 84 & 82.36 & \\
\hline 46-50 hours & 9 & 8.82 & \\
\hline \multicolumn{4}{|c|}{ Hours of overtime per week } \\
\hline No overtime & 62 & 60.79 & \multirow{3}{*}{$1.28 \pm 2.31$} \\
\hline 1-5 hours & 31 & 30.39 & \\
\hline 6-10 hours & 9 & 8.82 & \\
\hline
\end{tabular}




\begin{tabular}{|c|c|c|c|}
\hline Score Range & Stress Category & Number & Percentage \\
\hline 14 & No Stress & 0 & 0 \\
\hline $15-32$ & Mild Stress & 2 & 1.96 \\
\hline $33-50$ & Moderate Stress & 54 & 52.95 \\
\hline $51-70$ & Severe Stress & 46 & 45.09 \\
\hline
\end{tabular}

TABLE 4 ASSOCIATION BETWEEN LEVEL OF STRESS WITH DEMOGRAPHIC VARIABLES $(\mathrm{N}=102)$

\begin{tabular}{|c|c|c|c|c|c|c|}
\hline $\begin{array}{l}\text { Demographic } \\
\text { variables }\end{array}$ & No Stress & Mild Stress & $\begin{array}{l}\text { Moderate } \\
\text { Stress }\end{array}$ & $\begin{array}{l}\text { Severe } \\
\text { Stress }\end{array}$ & Chi Square & $\begin{array}{l}\text { Spearmen } \\
\text { correlation }\end{array}$ \\
\hline & & & & & (P value) & (P value) \\
\hline \multicolumn{7}{|c|}{ Age Wise Distribution } \\
\hline $20-30$ & 0 & $1(50)$ & $31(57.4)$ & 34 (73.9) & 7.26 & -0.18 \\
\hline $30-40$ & 0 & $1(50)$ & $14(25.9)$ & $8(17.4)$ & -0.29 & -0.06 \\
\hline $40-50$ & 0 & $0(0)$ & $4(7.41)$ & $4(8.7)$ & & \\
\hline $50-60$ & 0 & $0(0)$ & $5(9.26)$ & $0(0)$ & & \\
\hline Total & 0 & $2(100)$ & $54(100)$ & $46(100)$ & & \\
\hline \multicolumn{7}{|c|}{ Gender wise distribution } \\
\hline Male & 0 & $0(0)$ & $21(38.9)$ & $23(50)$ & 2.79 & -0.14 \\
\hline Female & 0 & $2(100)$ & $33(61.1)$ & $23(50)$ & -0.24 & -0.15 \\
\hline Total & 0 & $2(100)$ & $54(100)$ & $46(100)$ & & \\
\hline
\end{tabular}

TABLE 5 ASSOCIATION BETWEEN LEVEL OF STRESS WITH WORKING PATTERN (N = 102)

\begin{tabular}{|c|c|c|c|c|c|c|}
\hline Working pattern & No Stress & $\begin{array}{l}\text { Mild } \\
\text { Stress }\end{array}$ & $\begin{array}{c}\text { Moderate } \\
\text { Stress }\end{array}$ & $\begin{array}{l}\text { Severe } \\
\text { Stress }\end{array}$ & Chi Square & $\begin{array}{l}\text { Spearmen } \\
\text { correlation }\end{array}$ \\
\hline & & & & & (P value) & (P value) \\
\hline \multicolumn{7}{|c|}{ Years of Experience } \\
\hline Less than 5 year & 0 & $1(50)$ & 28 (51.9) & $30(65.2)$ & 2.96 & -0.14 \\
\hline 5 to 10 years & 0 & 0 & $10(18.5)$ & $6(13.1)$ & -0.56 & -0.15 \\
\hline More than 10 years & 0 & $1(50)$ & $16(29.6)$ & $10(21.7)$ & & \\
\hline Total & 0 & $2(100)$ & $54(100)$ & $46(100)$ & & \\
\hline \multicolumn{7}{|c|}{ Shift timing } \\
\hline Rotating 8 hours shift & 0 & $2(100)$ & $38(70.4)$ & $33(71.8)$ & 5.01 & -0.01 \\
\hline Rotating 12 hours shift & 0 & 0 & 0 & $2(4.3)$ & -0.54 & -0.92 \\
\hline Permanent day shift & 0 & 0 & $16(29.6)$ & $10(21.7)$ & & \\
\hline Permanent evening shift & 0 & 0 & 0 & $1(2.2)$ & & \\
\hline Permanent night shift & 0 & 0 & 0 & 0 & & \\
\hline Total & 0 & $2(100)$ & $54(100)$ & $46(100)$ & & \\
\hline \multicolumn{7}{|c|}{ Shift change in a week } \\
\hline Does not change & 0 & $1(50)$ & 21 (38.9) & $12(26.1)$ & 5.15 & 0.19 \\
\hline 2 times & 0 & 0 & $8(14.8)$ & $8(17.4)$ & -0.74 & -0.04 \\
\hline More than 2 times & 0 & $1(50)$ & $17(31.5)$ & $14(30.5)$ & & \\
\hline On call & 0 & 0 & $5(9)$. & $10(21.7)$ & & \\
\hline In stand by & 0 & 0 & $3(5.5)$ & $2(4.3)$ & & \\
\hline Total & 0 & $2(100)$ & $54(100)$ & $46(100)$ & & \\
\hline \multicolumn{7}{|c|}{ Working hours per week } \\
\hline $36-40$ hours & 0 & 0 & $1(1.9)$ & $7(15.2)$ & 6.28 & -0.22 \\
\hline 41-45 hours & 0 & $2(100)$ & $46(85.2)$ & $37(80.5)$ & -0.17 & -0.02 \\
\hline $46-50$ hours & 0 & 0 & $7(12.9)$ & $2(4.3)$ & & \\
\hline Total & 0 & $2(100)$ & $54(100)$ & $46(100)$ & & \\
\hline \multicolumn{7}{|c|}{ Hours of overtime per week } \\
\hline No overtime & 0 & $2(100)$ & $36(66.7)$ & $24(52.2)$ & 8.62 & 0.12 \\
\hline 1-5 hours & 0 & 0 & $11(20.4)$ & $20(43.5)$ & -0.07 & -0.21 \\
\hline $6-10$ hours & 0 & 0 & $7(12.9)$ & $2(4.3)$ & & \\
\hline Total & 0 & $2(100)$ & $54(100)$ & $46(100)$ & & \\
\hline
\end{tabular}




\section{Figures}

FIGURE 1 DISTRIBUTION OF STUDY PARTICIPANTS ACCORDING TO THEIR WORKING AREA/DEPARTMENT $(N=102)$

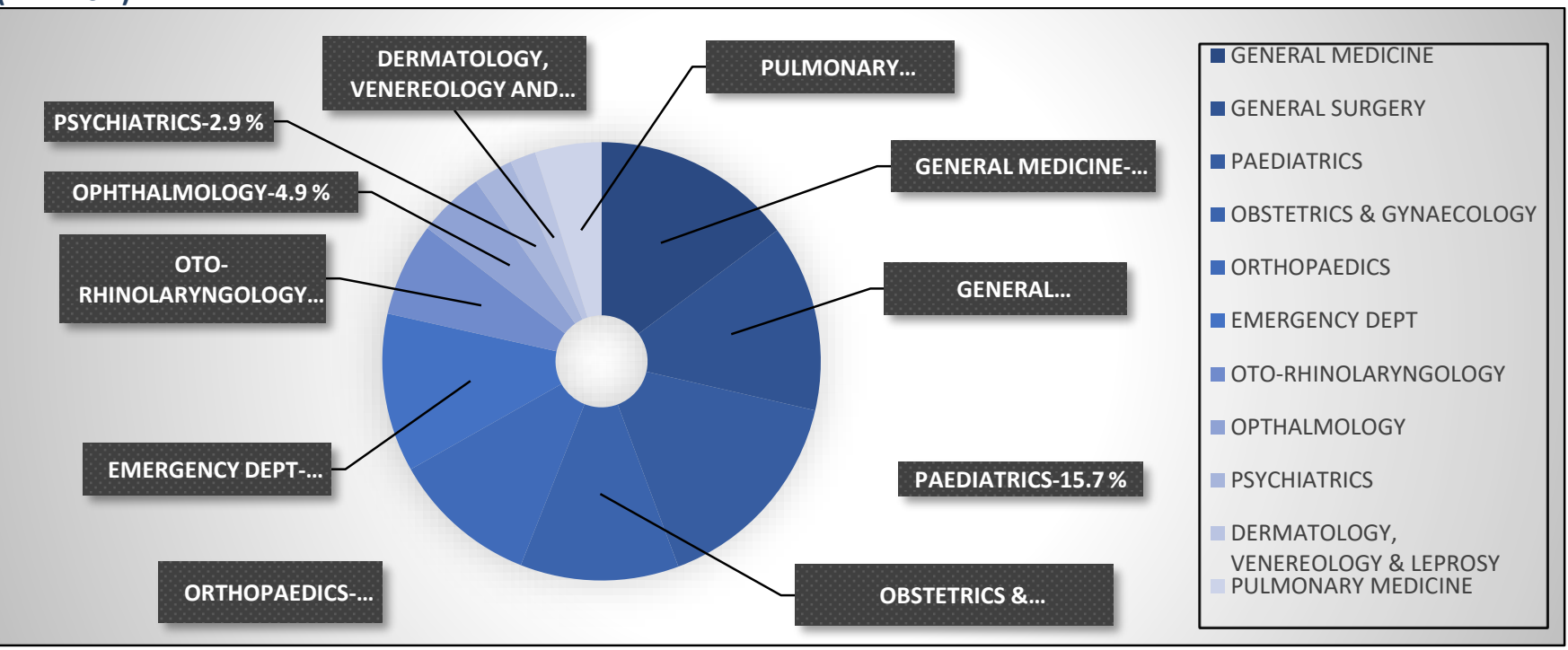

